\title{
Effects of Indomethacin in Utero on the Pulmonary Vasculature of the Newborn Guinea Pig
}

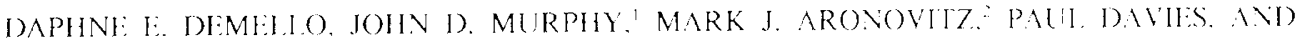 \\ L.V.VE: M. RIII)

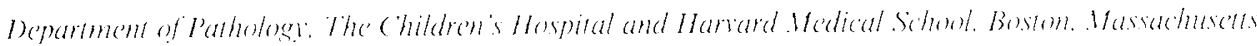

\begin{abstract}
ABSIRACI. The clinical syndrome of persistent pulmonary hypertension of the newborn results from failure of the normal perinatal vascular adaptation, and functionally is characterized by persistent right to left shunting of blood through the foramen ovale and ductus arteriosus. Exposure of the fetus to drugs that inhibit prostaglandin synthesis and cause closure of the ductus arteriosus has been suggested as one cause of persistent pulmonary hypertension of the newborn. We attempted to produce a functional and structural model of persistent pulmonary hypertension of the newborn by administration of indomethacin, a cyclooxygenase inhibitor, to pregnant guinea pigs. Five pregnant guinea pigs received $3.5 \mathrm{mg} / \mathrm{kg}$ indomethacin intravenously twice each day for the 12 to 19 days before delivery and seven controls received saline. Ilemodynamic studies were performed in eight "treated" newborns and in 12 controls. After sacrifice, the ductus was ligated and, for morphometric studies, the pulmonary arteries were distended with barium/gelatin. The treated animals did not show the intraacinar structural or hemodynamic changes of persistent pulmonary hypertension of the newborn. It seems that the indomethacin did cross the placenta because lung structure was modified. The radial alveolar count and alveolar/artery ratio were increased and the preacinar arteries dilated, with more increase in muscle mass. This could be explained by increased pulmonary blood flow because of ductal constriction but direct effect of indomethacin cannot be excluded. (Pediatr Res 22: 693-697, 1987)
\end{abstract}

\section{Abbreviations}

PPIIN, persistent pulmonary hypertension of the newborn Rx, treated

C, control

$\mathrm{RAC}$, radial alveolar count

$\mathrm{IV}$, intravenous

Ppa, pulmonary artery pressure

Psa, systemic artery pressure

LD, external diameter

At birth as the lungs expand with air and mediators that include bradykinin are released, pulmonary vascular resistance

Received $\wedge$ pril 27. 1987: accepted July: 30. 1987.

Gorrepondence and reprints I yne Reid. M.D). The (hildren's Hospital, Department of Pathology. 300) I.ongwood Avenue. Boston. MA (12115.

Supported by SCOR (irant H1 . 32364-()4 from Heart. I ung and Blood Division of the National Institutes of Health.

Present address Division of (ardiology. ( hildren's Hospital of Philadelphia. 34th Street and (ivic (enter Boulevand. Philadelphial, PA.

?Present address Department of (ardiology. New Fongland Medical center. Boston, $\mathrm{M} \wedge$ falls because of vasodilatation and increased compliance of small resistance arteries (1-4). The increased compliance is indicated by an increase in the diameter and a drop in watl thick ness of arteries at a given distending pressure.

Idiopathic PPHA results when this perinatal adaptation fails and right to left shunting occurs through the foramen owale and/ or ductus arteriosus. Sometimes it is fatal $(5-7)$. and in these cases in addition to any functional falure. the arterial bed is usually structurally abnormal with a well-developed medial muscle coat present in intracinar arteries that at birth are normally not muscular. The pre-and intracinar arteries are abnormally small and arteries of all sice have a dense collagen sheath (8. 9). indicating that resistance arteries fail to increase compliance

Indomethacin and other evelooxygenase inhibitors have been shown to cause constriction of the ductus arteriosus of experimental animals and a rise in pulmonary artery pressure in utere (10. 11). This led these authors and others (12) to suggest that premature closure or constriction of the ductus arteriosus might be a cause of PPH I in humans, although they had not identified in animals the human structural changes described above. In some cases of PPHA the mother had ingested erelooxigenase inhibitors $(13-17)$. Other authors (18. 19) have not found this association. Most reports describe the functional effects of indemethacin exposure and not the structural changes in the pulmonary arteries. In ritro, the guinea pig ductus secms not to be affected by indomethacin (20), but this effect has not been studied in vivo. We have administered indomethacin to guinea pigs late in pregnancy and have evaluated the newborns for possible structural and hemodinamic features of PPHN.

\section{MFHIOLS}

We used 12 pregnant guinea pigs. About 3 wh before delivers a pregnant guinea pigs was allocated to an Rx or ( group. Seren mothers receised $2 \mathrm{ml}$ of saline. IV twice a day, until delivery. The 12 guinea pigs born to these mothers who had received IV saline for periods ranging from 6-23 days constituted the (ontrol group.

This study is based on four pregnant guinea pigs treated with IV indomethacin. $3.5 \mathrm{mg} / \mathrm{kg}$ twice a day until delivery and a fifth animal that received indomethacin both orally and IV (2 $\mathrm{mg} / \mathrm{kg}$ IV . h.i.d. for 9 days and $3 \mathrm{mg} / \mathrm{kg}$ b.i.d. orally for 7 days). The dosage was based on a series of preliminary studies in a separate group of pregnant guinca pigs. Starting dose wass 6.5 $\mathrm{mg} / \mathrm{kg}$ once or twice a day. This was reduced by $0.5 \mathrm{mg}$ increments until all offspring were liveborn. at $3.5 \mathrm{mg} / \mathrm{kg}$. The highest dose proved fatal to the mother and the intermediate doses were fatal to the fetuses. In aborted fetuses from at kast three litters. the ductus was closed

The treated group yielded eight newborns that had been exposed in utero to indomethacin for 12 to 19 days. All the newborns were delivered spontaneously. Within 5 h of birth the 
newborn guinea pigs were weighed and studied hemodynamically. They were maintained under a radiant warmer throughout the study.

The newborn guinea pigs were anesthetized with sodium pentobarbital, $10 \mathrm{mg} / \mathrm{kg}$ intraperitoneally and lidocaine $0.5 \%$ locally. Silastic catheters (external diameter $0.56 \mathrm{~mm}$ ) were placed in the left carotid artery and the main pulmonary artery using techniques similar to those described previously (21). Pressures were recorded from the pulmonary artery, right ventricle, right atrium, and systemic arteries. Blood samples were drawn from the systemic arteries, pulmonary artery, and right atrium for blood gas determinations, oxygen saturation, and hemoglobin concentration.

Following the hemodynamic studies, the animals were sacrificed with an overdose of sodium pentobarbital $(300 \mathrm{mg} / \mathrm{kg})$ at ages ranging from $>1$ to $5 \mathrm{~h}$. When respiration ceased the chest was opened and the heart and lungs removed en bloc, the ductus was ligated and the pulmonary arteries were injected with a barium gelatin suspension at a pressure of $73.5 \mathrm{~mm} \mathrm{Hg}$. The lung was fixed fully distended by intratracheal instillation of $10 \%$ buffered formalin at $25 \mathrm{~cm}$ water pressure (22). Pulmonary arteriograms were obtained. The diameter of the axial pulmonary artery at the first branch and at 50 and $75 \%$ of the distance to the periphery was measured on pulmonary arteriograms. After fixation, lung volumes were measured by water displacement and four blocks were taken, one each from the left cranial and caudal lobes and two from the right lower lobe. Four $\mu$ m sections were cut and stained with hematoxylin and eosin and Miller's elastic-van Gieson stain. Morphometric analysis of the pulmonary vasculature using light microscopy was performed according to the methods developed by Hislop and Reid (23-25). Briefly, in each of four sections the barium-filled arteries under $300 \mu \mathrm{m}$ in diameter were examined (about 70/animal), structure was recorded, medial thickness measured, and percentage medial thickness was calculated using the formula $2 \times$ medial thickness $\times 100 /$ external diameter. The airway was identified and the accompanying arteries grouped by airway level as preacinar (terminal bronchiolus, respiratory bronchiolus), alveolar duct, or alveolar wall. Radial alveolar counts were performed according to the method of Emery and Mithal (26). The structure of the pulmonary veins was also examined.

Each heart was dissected and weights of the right ventricular free wall, and left ventricle + septum, were recorded.

The data in the two groups were compared using the Wilcoxon Rank sum test (27) and Student's $t$ distribution, including a Bonferroni correction for multiple comparisons (28). For the latter, SD was used as the index of dispersion, the tests were unpaired and a 5\% significance level was used.

\section{RESULTS}

Body weights of the $\mathrm{Rx}$ animals were similar to the $\mathrm{C}$ group ( $R x: 88.5 \pm 8.7$ and $C: 87.8 \pm 14.1$, respectively), as were cardiac ventricular weights. The mean hematocrit for the treated animals was somewhat higher than that of the controls but not significantly so (Rx: $46 \pm 5.19 \%$, C: $42.6 \pm 2.69 \%$ ). Arterial pH was similar in animals of both groups ( $\mathrm{Rx}: 7.4 \pm 0.02, \mathrm{C}: 7.38 \pm$ $0.06)$, as were the arterial $\mathrm{pO}_{2}$, values ( $\mathrm{Rx}: 71.25 \pm 12.9 \mathrm{~mm} \mathrm{Hg}$, C: $74.2 \pm 22.2 \mathrm{~mm} \mathrm{Hg}$ )

Ppa and Psa were similar in the $\mathrm{Rx}$ and $\mathrm{C}$ groups (Ppa $\mathrm{Rx}$ :
$26.12 \pm 4.73 \mathrm{~mm} \mathrm{Hg}, \mathrm{C}: 26.83 \pm 4.0 \mathrm{~mm} \mathrm{Hg}$, Psa Rx: $48.7 \pm$ $10.3 \mathrm{~mm} \mathrm{Hg}, \mathrm{C}: 46.5 \pm 6.34 \mathrm{~mm} \mathrm{Hg}$ ) (Table 1).

Morphometric findings. Lung volumes were similar in the $\mathrm{Rx}$ and $\mathrm{C}$ groups (Rx: $4.0 \pm 0.6 \mathrm{ml}, \mathrm{C}: 3.88 \pm 0.031 \mathrm{ml}$ ) (Fig. 1).

The ductus was open in all animals and was ligated before the preliminary arterial injection was made. Measurement of axial artery luminal diameter on the arteriograms showed greater values in the $\mathrm{Rx}$ group that in the $\mathrm{C}$ in five of the six levels. In the left artery at the most proximal level, the difference was very close to significant using the Bonferroni correction (Table 2).

The percentage of muscular arteries at each airway level was similar in both groups indicating that intrauterine exposure to indomethacin had not caused abnormal muscularization. In both groups the intraacinar vessels were similar in external diameter and percentage medial thickness (Table 3).

Although the percent medial thickness of preacinar arteries in both the treated and control animals was similar, the ED of the preacinar arteries in the $\mathrm{Rx}$ group was larger indicating some increase in smooth muscle mass in preacinar arteries (Table 3). At this level the medial area was larger in the $\mathrm{Rx}$ than in the $\mathrm{C}$ group ( $\mathrm{Rx}: 9305.2 \pm 6746.2$, C: $5215.1 \pm 5357.9, p<0.001$ ).

In seven of the eight animals in the Rx group alveolar multiplication had exceeded that of the $C$ animals. The mean RAC for the Rx group was 19 , significantly above the control value of $15.68(p<0.05)$. The alveoli were smaller and alveolar number per unit area was higher, as was obvious from inspecting fields of similar size (Fig. 2).

The alveolar to arterial ratio was higher in the $\mathrm{Rx}$ group than the $\mathrm{C}$ guinea pigs ( $\mathrm{Rx}: 124 \pm 58.1, \mathrm{C}: 76 \pm 17.1, p<0.05)$. Since the arterial density per unit area of lung did not differ in the two groups the increased ratio reflects the increased alveolar density. The veins and perivascular collagen were similar in the $\mathrm{Rx}$ and C groups.

In summary, the Rx animals had an increase in diameter of the left pulmonary artery and preacinar arteries of both lungs with increased muscle mass in preacinar arteries and an increase in alveolar multiplication to give abnormally high radial alveolar counts. They did not show muscularization of intraacinar arteries or increase in perivascular collagenous sheaths.

\section{DISCUSSION}

The administration of indomethacin to pregnant animals causes ductal constriction and an elevation of fetal pulmonary artery pressure $(11,29-33)$. Indomethacin may also lead to intrauterine ductal constriction in humans $(13,14,34)$. Since postnatal Ppa after intrauterine exposure to indomethacin has not previously been reported, the effect of intrauterine indomethacin on the perinatal pulmonary vascular adaptation is not known.

Pulmonary arterial wall thickness has been reported as increased after exposure to indomethacin in utero in sheep (11), rats (12), and human infants (14). Since these vessels had not been distended before fixation and since the external diameter of the pulmonary vessels was decreased (11), this effect could be due to vasoconstriction alone. From the data given (11), the calculated mean cross-sectional area of the muscular media in controls is $665.92 \mu \mathrm{m}^{2}$ and in experimental animals, $732 \mu \mathrm{m}^{2}$, a difference that is not statistically significant $(p>0.05)$. In another study in fetal rats, vessels of similar external diameter

Table 1. Hemodynamic data

\begin{tabular}{|c|c|c|c|c|c|}
\hline & $\begin{array}{c}\text { Mean } \\
\text { hematocrit } \\
(\%) \\
\end{array}$ & $\begin{array}{c}\text { Mean } \\
\text { arterial } \\
\mathrm{pH}\end{array}$ & $\begin{array}{c}\text { Mean } \\
\text { arterial pO } \\
(\mathrm{mm} \mathrm{Hg})\end{array}$ & $\begin{array}{c}\text { Mean Ppa } \\
(\mathrm{mm} \mathrm{Hg})\end{array}$ & $\begin{array}{l}\text { Mean Psa } \\
(\mathrm{mm} \mathrm{Hg})\end{array}$ \\
\hline Indomethacin Rx & $46.0 \pm 5.1$ & $7.40 \pm 0.02$ & $71.2 \pm 12.9$ & $26.1 \pm 4.7$ & $48.7 \pm 10.3$ \\
\hline $\mathrm{C}$ & $42.6 \pm 2.6$ & $7.38 \pm 0.06$ & $74.2 \pm 22.2$ & $26.8 \pm 4.0$ & $46.5 \pm 6.3$ \\
\hline
\end{tabular}



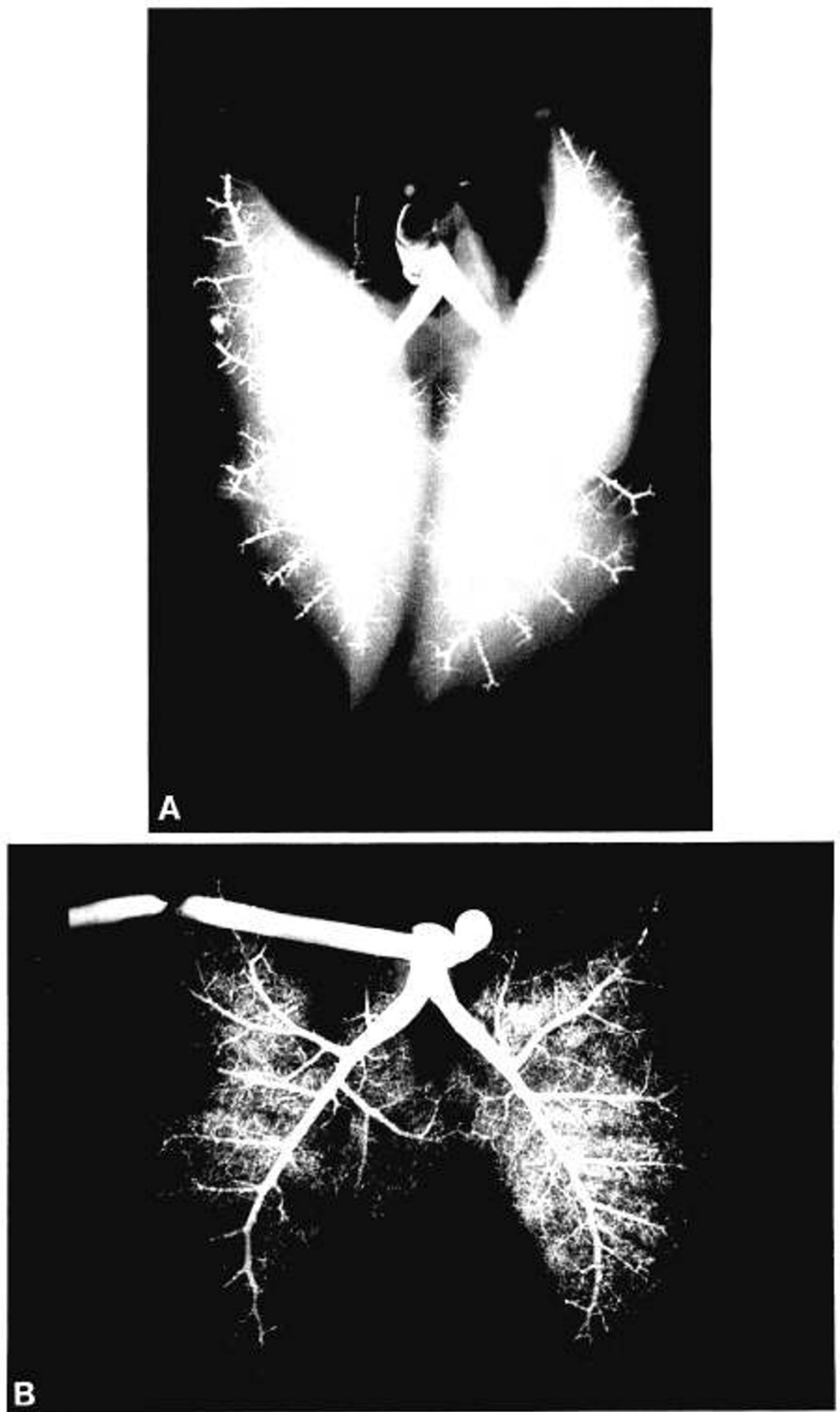

Fig. 1. Pulmonary arteriograms of $(.1)$ indomethacin-treated guinea pig showing lumen diameter of left pulmonary artery 799$) \mu \mathrm{m}$ and $(B)$ control, lumen diameter $73.3 \mu \mathrm{m}(\times 4)$.

Table 2. txial arterl-Luminal diameter $(\mu m)$

Left

$\Lambda t$ ist branch

Indomethatcin $\mathrm{Rx}$ ('
$924 \pm 1.30 .5$

$714+160.7$
$50 \%$

$649 \pm 99.1$

$545+114.7$
$75 \%$

$408 \pm 109.4$ $369 \pm 150.0$
At lst branch

$774 \pm 123.0$

$696+127.6$
Right

$50)^{\circ}$

$6.33 \pm 71.2$ $557 \pm 1006$
$75 \%$

$391 \pm 97.1$ $4(x) \pm 16.3 .1$ 
were compared in experimental animals and controls. Although the calculated percent wall thickness was increased in the experimental group, since the vessels were not landmarked by the accompanying airway, it is not certain that vessels of the same level were being compared. Thus it is again possible that the observed difference is due to vasoconstriction rather than a true

Table 3. Microscopic artery measurements

\begin{tabular}{|c|c|c|c|c|}
\hline & \multicolumn{2}{|c|}{ Preacinar } & \multicolumn{2}{|c|}{ Intraacinar } \\
\hline & $\begin{array}{c}\mathrm{ED} \\
(\mu \mathrm{m})\end{array}$ & $\begin{array}{l}\mathrm{MT}^{*} \\
(\%)\end{array}$ & $\begin{array}{c}\mathrm{ED} \\
(\mu \mathrm{m})\end{array}$ & $\begin{array}{l}\text { MT } \\
(\%)\end{array}$ \\
\hline $\begin{array}{l}\text { Indomethacin } \mathrm{Rx} \\
\mathrm{C}\end{array}$ & $\begin{array}{l}191.4 \pm 52.4^{*} \\
117.5 \pm 55.8\end{array}$ & $\begin{array}{r}9.9 \pm 3.1 \\
10.8 \pm 2.6\end{array}$ & $\begin{array}{l}35.3 \pm 21.8 \\
38.7 \pm 11.2\end{array}$ & $\begin{array}{l}20.1 \pm 6.4 \\
16.4 \pm 5.8\end{array}$ \\
\hline
\end{tabular}

* Medial thickness. $p<0.02, t$ test. increase in vascular smooth muscle or extension of muscle into normally nonmuscular arteries. We report for the first time an increase in medial muscle mass of normally muscular arteries after indomethacin administration, but it is associated with diffuse enlargement of the lumen in large arteries and not contracture of the arterial bed.

Contrary to our expectations, our study did not produce postnatal pulmonary hypertension or the structural changes, particularly the excessive muscle of intraacinar arteries, that are typical of human PPHN $(8,9,35)$. It is unlikely that indomethacin failed to cross the placenta. Our preliminary experiments with higher doses $(8 \mathrm{mg} / \mathrm{kg} /$ day) resulted in an aborted fetus with closed ductus. The modification to pulmonary structure by indomethacin treatment indicates that indomethacin crossed the placenta and was effective. Several studies have shown that indomethacin crosses the placenta and produces ductal constriction thus increasing pulmonary blood flow $(11,30-33,36)$.

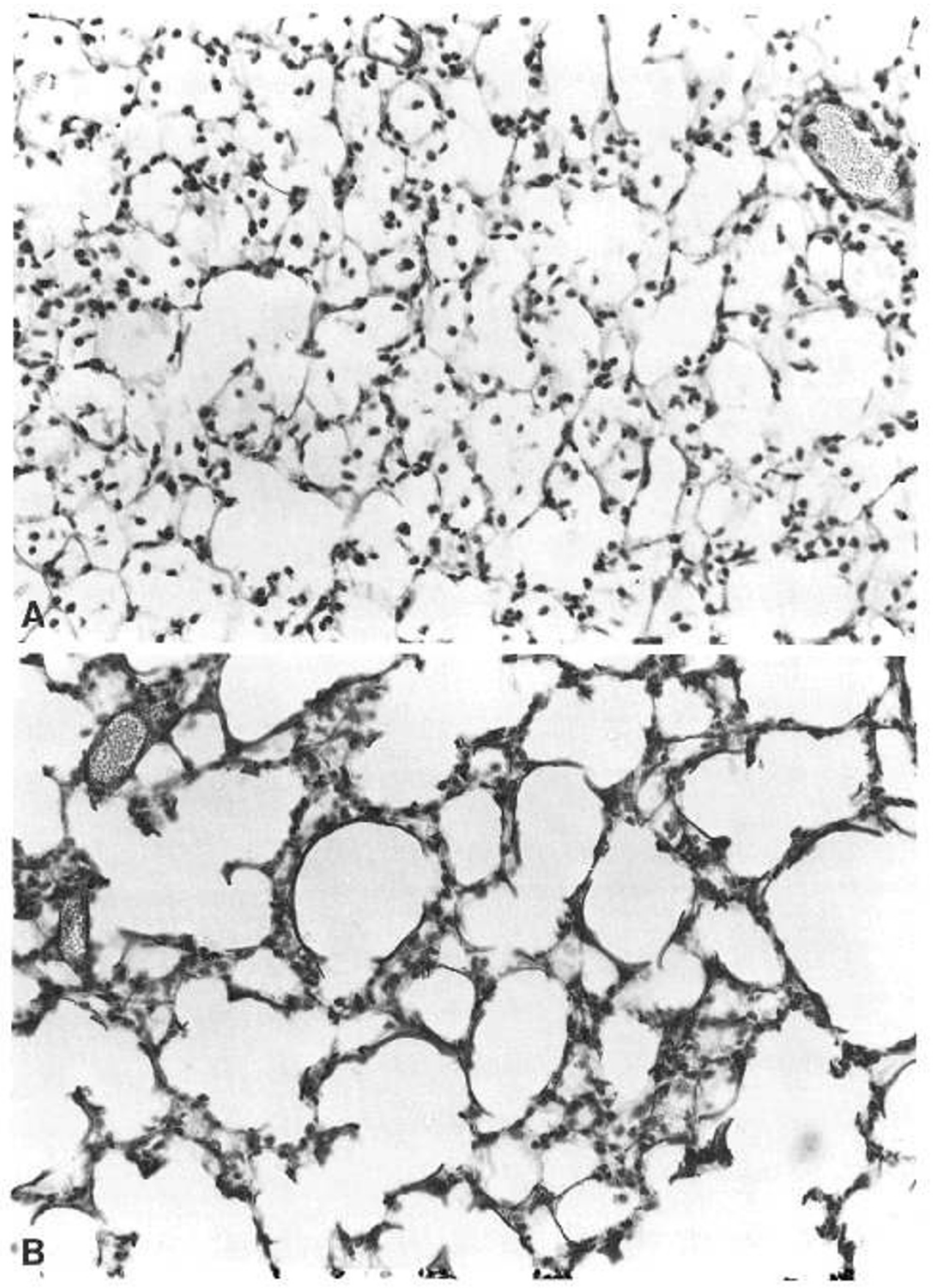

Fig. 2. Photomicrograph of lung: $(A)$ indomethacin-treated guinea pig showing increased alveolar density per unit area of lung compared with $(B)$ control $(\times 250$, Miller's clastic-van Gieson stain). 
Postnatally the Ppa in both $\mathrm{Rx}$ and ('animals was similar. indicating that regardless of intrauterine flow postnatal adaptation occurred to give normal Ppa. The increase in $\mathrm{R} \wedge \mathrm{C}^{\prime}$ in the $\mathrm{Rx}$ animals indicates greater than normal alveolar multiplication. a phenomenon not previously described after fetal indomethacin exposure. Whether this is a direct effect of indomethacin or evidence of an increased dose of growth hormones because of increased flow is not known. Rudolph (37) has suggested that there are differences in the biologic response to indomethacin by small pulmonary vessels due to the duration of ingestion. gestational age of the fetus, and time interval between the last dose of the drug and birth: each can alfect the nature of the response of the pulmonary circulation.

There is dissociation between multiplication of alveoli and appearance of small alveolar wall vessels. A similar dissociation has been reported in other conditions: an increase in alveolar to arterial ratio was found in polyalveolar lobe where alveolar multiplication is excessive (23), with a raised alveolar to arterial ratio. It is tempting to speculate that the increased pulmonary flow in ufere consequent to ductal constriction had a similat effect. It could of course be a direct effect on alveolar growth control by indomethacin. $A$ decreased number of pulmonary vessels/ $\mathrm{cm}^{2}$ lung tissue has been described in a human newborn after chronic intraterine exposure to a cyclooxvgenase inhibitor (14). Alveolar number was not estimated.

While the increased diameter of preacinar arteries in our $R x$ animals could be a rapid change. the increase in muscte mass is likely to have taken place over several days to weeks. Since the animals were killed a few hours after birth, it is likely that these changes occurred in llfere.

In summary chronic in utere exposure of guinea pigs to indomethacin produced neither the hemodynamic nor structural changes of PPIIN. It seems that indomethacin acted long enough in thero to modify the pulmonary arterial bed and cause increased alveolar multiplication. These findings suggest that the changes produced by increased blood llow are not the ones that cause PPIN: the structural changes in the latter of muscularized but small peripheral intracinar arteries and dense collagen sheaths are so different from those seen after intrauterine indomethacin treatment that they do not even suggest early changes of PPIfN.

\section{RIFERINVC IS}

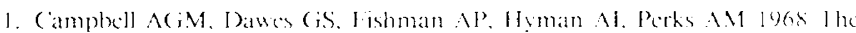
relcase of a bradykintetike pulmonary vasedilator substance in fetal and newborn lambs. J Phosiol 195:8.3-96

2. Hevmann MA Rudolph AM Vies AS. Melmon Kl loge Bradvinin proxduction associated with ox gegenation of the fetal lamb. (irc Res $25: 521-5.34$

3. Cassin S. Dawes (iS. Mott J. Ross BB, Strang 1 B 1964 The vasculan resistance of the fetal and newly wentilated lung of the lamb. J Phosiol 171:61-79

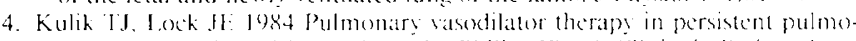
nary hypertension of the newborn. In: Philips.JB (ed) (linics in Perinatologs. Vol I1/3 Sumposium on Vionatal Pulmonary Hypertension. H'B Saunders. Philadelphia. po 6933.701

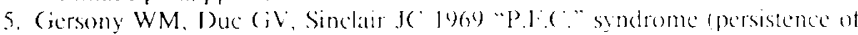
the fetal circulation). (irculation 40:87(ahstr)

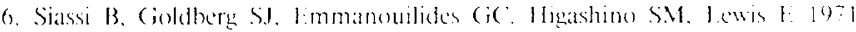
Persistent pulmonary vascular obstruction in newborn infants. I Pediatr $78:(6) 1(0-6) 15$

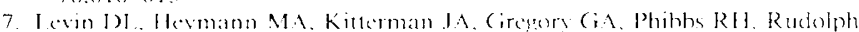
AM 1976 Persistent pulmonary hypertension of the newbern inlant. I Pedtatt $89: 626-6.30$

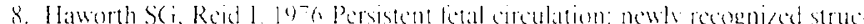
tural feat ures. \& Pediatr $88: 61+620$

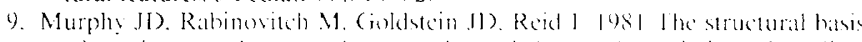
of persistent pulmonary hepertension of the newhorn infant. I Padiat $98 \cdot 962 \ldots 96$ ?

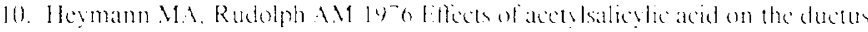

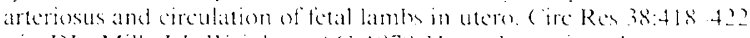

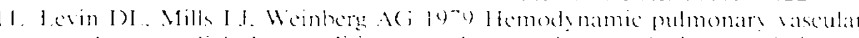
and myocardial abnormalities scondare of pharmacologie constriction of

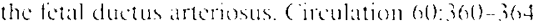

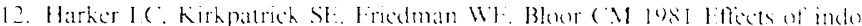
methacin on fetal rat lungs: a possible ause of persiskm fetal cinculation

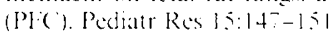

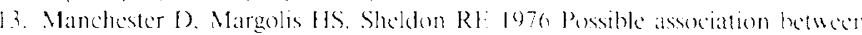
maternal indomethacin theraps and priman pulmonars he pertension of the newborm. Am I ()bsted (ivnecol 226:46- 460

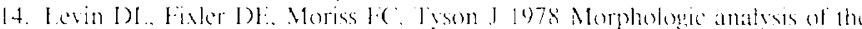
pulmonary vascular bed in intants exponed in utero bo prostaglandin synthetase inhibitors. 3 pediate y $2: 4^{-} 8+48$ ?

15. (saba If: Sulyok I: latt l 1978 Relationship of maternal treatment with

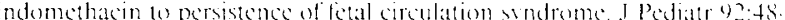

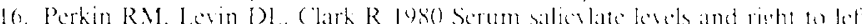
dectus shunts in newborn infants with persistent pulmonars hepertenson. J Pediatr $96: 7 \geq 1-720$

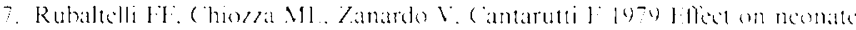
of maternal treatment with indomethaten. I Pedate $94: 16$ !

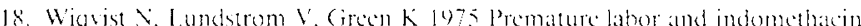
Prostaglandin $10: 515250$

19. Kumor K.M. White R1). Blake () I $10^{-9}$ Indomethacin as a treatment for premature babur. Veonatal outeome. Pediate Res 1,3:3704abstr)

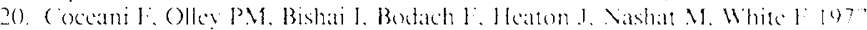
Prostaglandins and the conter of muste lone in the dectus arterimess. Wh (x) Med Biol $78: 13=-14$ ?

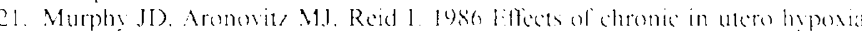
on the pulmonary vasculature of the newbern gumea pig. Pediate Re 2(1):202-205

22. Davies (i. Reid 1. 1970 (irowth of the alseole and pulmonary arteries in

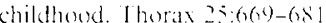

23. Hiskop) 1. Reid I 1970 New pathological tindings in :mphe sema of childhoud 1. Polyalveolar lobe with emphysema. Thorax $25: 6 \$ 2-690)$

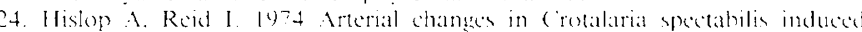

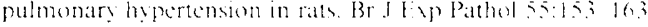

3 Hislop A. Reid I 1970 Vow findinge in pulmonare artertes of rats with hopova

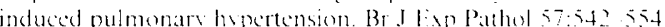

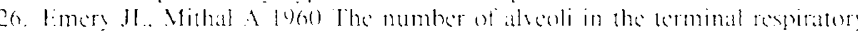
unit of man during late intraterine life and childhend. Arch Dos (hile $35 \div 544-547$

27. Wilcoson $\mathrm{F}$ 1945 Individuat comparisom be ranhing methods. Biometr Bull $1: 8(1)$

28. Wallenstein S. Zucher ( Feiss J1 1980 Some statistical methods useful in circulation research. (inc Res $\left.t^{-}: 1-0\right)$

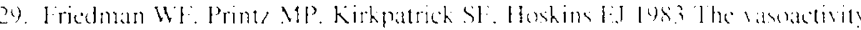

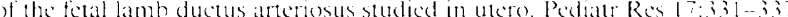

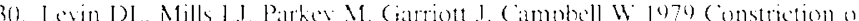
the retal ductue arteriosus after administration of indomethacin to the pregnant ewe. I Pediate $4:\left(14^{-}-6,50\right.$

31. Kirkpatrick SE. Print/ MP. Friedman HI: I977 Prostaghandins (Pys) and the fetal ductus arterioness (PI) 1). Pediate Res 11 :39.4(atatr

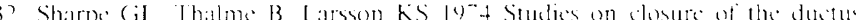

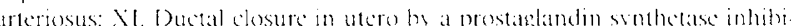
tor Prostizulandins s $30 ;-30,8$

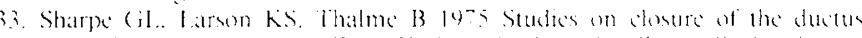
arteriosus Xll. In utero ctfect of indomethacin and sodium salicylate in rats and rabhits. Prostaglandins $9: 585-590$

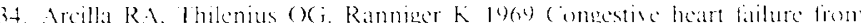

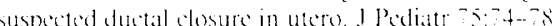

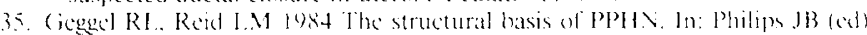

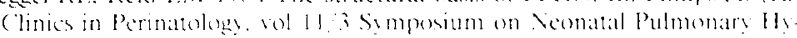
pertemsion. WB Saunders. Philadelphia. pp $525 . .540$

36. Parks BR, Jordan RI. Rawson JE. Douglas BH 1977 Indomethasin: Studies

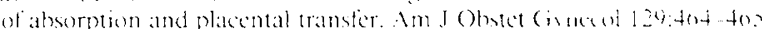

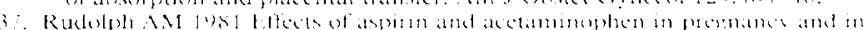
the newhorn. Arch Intern 19d 1+1:35s-36:3 